\title{
Computational contact mechanics for a medium consisting of functionally graded material coating and orthotropic substrate
}

\author{
Erdal Öner * \\ Bayburt University, Department of Civil Engineering, Bayburt, Turkey
}

\begin{abstract}
This paper presents a semi-analytical method to investigate the frictionless contact mechanics between a functionally graded material (FGM) coating and an orthotropic substrate when the system is indented by a rigid flat punch. From the bottom, the orthotropic substrate is completely bonded to the rigid foundation. The body force of the orthotropic substrate is ignored in the solution, while the body force of the FGM coating is considered. An exponential function is used to define the smooth variation of the shear modulus and density of the FGM coating, and the variation of Poisson's ratio is assumed to be negligible. The partial differential equation system for the FGM coating and the orthotropic substrate is solved analytically through Fourier transformations. After applying boundary and interface continuity conditions to the mixed boundary value problem, the contact problem is reduced to a singular integral equation. The Gauss-Chebyshev integration method is then used to convert the singular integral equation into a system of linear equations, which are solved using an appropriate iterative algorithm to calculate the contact stress under the rigid flat punch. The parametric analyses presented here demonstrate the effects of normalized punch length, material inhomogeneity, dimensionless press force, and orthotropic material type on contact stresses at interfaces, critical load factor, and initial separation distance between FGM coating and orthotropic substrate. The developed solution procedures are verified through the comparisons made to the results available in the literature. The solution methodology and numerical results presented in this paper can provide some useful guidelines for improving the design of multibody indentation systems using FGMs and anisotropic materials.
\end{abstract}

\section{Keywords}

Critical load factor; FGM coating; Flat punch; Initial separation distance; Orthotropic substrate

Received: 23 October 2021; Accepted: 16 December 2021

ISSN: 2630-5763 (online) (C) 2021 Golden Light Publishing All rights reserved.

\section{Introduction}

The field of contact mechanics, concerned with the deformation of solid materials that are placed in contact with one another, has a long history, dating back to the pioneering works of Hertz [1] and Boussinesq [2]. Contact mechanics issues can be classified based on a variety of factors. For example, the type of foundational material law (elastic/viscoelastic, homogeneous/inhomogeneous, degree of isotropy, etc.), the geometry of the applied load (normal contact, tangential contact, etc.), the friction and adhesion regime (frictionless, no-slip, etc.), or the shape of contacting bodies are all systematization categories [3]. The contact mechanics of homogeneous isotropic materials was a prominent issue when studies on contact mechanics were first investigated. Regarding the literature on the

\footnotetext{
Corresponding author

Email: eoner@bayburt.edu.tr
} 
theoretical investigations of the contact mechanics, problems involving isotropic materials are well investigated by [4-9]. The reader should consult the studies [10-17] for sliding contact, partial slip contact, rolling, and rolling tractive contact. Also, for frictional, elastodynamic, and thermoelastic contact problems, [18-20] papers should be read. However, in parallel with the progress of science and technology, there has been a tendency toward new innovative materials in studies in contact mechanics. As a result, studies on the contact mechanics of functionally graded materials (FGMs), a new type of composite material, was quickly introduced to the literature in the years that followed. FGMs are non-homogeneous composites that have been enhanced through the use of special deposition techniques. The primary advantage of graded materials over laminated composites is that the transition from one constituent to another can be smoothly tailored, thereby avoiding potential mismatch issues. Contact and indentation of FGMs have been studied to investigate the response of elastic graded coatings or interfacial layers using different material distributions, geometrical and loading conditions, and solution techniques. Frictionless and frictional contact problems of FGMs have been studied using semi-analytical solutions in [21-25]. In recent years, there has also been an increase in research interest in the contact of anisotropic materials.

Willis [26] attacked Hertz's problem for generally anisotropic bodies by a Fourier transform method. A solution to the frictionless contact of rigid flat indenters on arbitrarily layered, anisotropic half-planes using Fourier transforms and the local-global stiffness matrix technique is presented by Urquhart and Pindera [27]. Lin and Ovaert [28] investigated a method for solving the two-dimensional isothermal rough surface contact problem with friction in general anisotropic materials. Kahya et al. [29] investigated the frictionless receding contact problem between an anisotropic elastic layer and an anisotropic elastic half-plane when the two bodies are pressed together with a rigid circular stamp. A mathematical model which describes the frictional contact between the piezoelectric body and an electrically conductive foundation is considered by Migórski et al. [30]. Bagault et al. [31] developed a semi-analytical method for the contact problem of anisotropic elastic materials with an anisotropic coating. Li et al. [32] present the fundamental contact solutions of a magneto-electro-elastic half-space indented by a smooth and rigid half-infinite punch. Zhou and Lee [33] investigated the frictional sliding contact problem in monoclinic piezoelectric materials subjected to a rigid punch. The sliding frictional contact between a monoclinic coating/isotropic substrate system and a rigid cylindrical punch is examined by Yilmaz et al. [34]. A double frictional receding contact mechanics problem for a homogeneous orthotropic/isotropic system is investigated by Yildirim et al. [35]. Çömez and Yilmaz [36] considered the frictional contact problem of a half-plane that has monoclinic material property. Song et al. [37] investigate the two-dimensional frictionless contact problem of the piezoelectric half-plane under rigid flat and cylindrical punches. Cao et al. [38] present the frictional receding contact between a functionally graded elastic layer and an orthotropic substrate under the indentation of a rigid flat-ended stamp. The nonlinear partial slip contact problem between a monoclinic half-plane and a rigid punch of an arbitrary profile subjected to a normal load was solved by Çömez et al. [39]. Öner [40] investigated the receding contact problem of a homogeneous orthotropic coating resting on a homogeneous isotropic substrate without any interfacial defects.

Investigation of the literature indicates that there is no previous study related to the continuous contact mechanics between an FGM coating and an orthotropic substrate. These contact mechanics studies have great importance for the design of components in the field of tribology, automotive and aerospace industries. To fill this gap, we investigate the frictionless continuous contact problem of an FGM-coated orthotropic substrate indented by a normally loaded rigid flat punch using generalized plane strain conditions for the elasticity equations. The two-dimensional Navier's equations of equilibrium and boundary conditions 
are converted into a singular integral equation (SIE) of Cauchy type using Fourier integral transforms and then numerically solved to obtain the contact stress under rigid punch. A parametric study is conducted to highlight the effects of the normalized punch length, inhomogeneity parameters, dimensionless press force, and orthotropic material type on the contact stress, critical load factor, and initial separation distance.

In section 2, the outline of this study begins with a definition and mathematical formulation of the considered contact problem. Following that, the numerical solution to the resulting SIE is obtained (Sec. 3). Section 4 seeks to validate the semianalytical analysis against available literature results, as well as to discuss the effects of all influential parameters. Finally, the main conclusions of this investigation are summarized in section 5 .

\section{Statement and mathematical formulation of the problem}

Let us consider a rigid flat punch of length $2 \mathrm{a}$ penetrating FGM coating in the region $\mathrm{z}=\mathrm{h}_{1},|\mathrm{x}| \leq \mathrm{a}$, under the action of a normal force $\mathrm{P}$ and the plane strain problem described by Fig. 1, in which the $\mathrm{z}$ axis is assumed to be the axis of symmetry.

The Hertz contact stress on the top surface of the FGM coating is denoted by $\mathrm{p}(\mathrm{x})$ acting on the region $|x| \leq a$. The remainder of the top surface is traction-free. The FGM coating does not adhere to the orthotropic substrate. From the bottom, the orthotropic substrate is fully bonded to the rigid foundation. The body force of the orthotropic substrate was ignored while the body force of the FGM coating was considered. The heights of the FGM coating and orthotropic substrate are assumed to be $\mathrm{h}_{1}$ and $\mathrm{h}_{2}$, respectively. The shear modulus and mass density of the FGM coating are allowed to vary exponentially along its height direction as follows:

$$
\begin{array}{ll}
\mu_{1}(z)=\mu_{0} e^{\beta z}, & 0<z \leq h_{1} \\
\rho_{1}(z)=\rho_{0} e^{\Gamma z}, & 0<z \leq h_{1}
\end{array}
$$

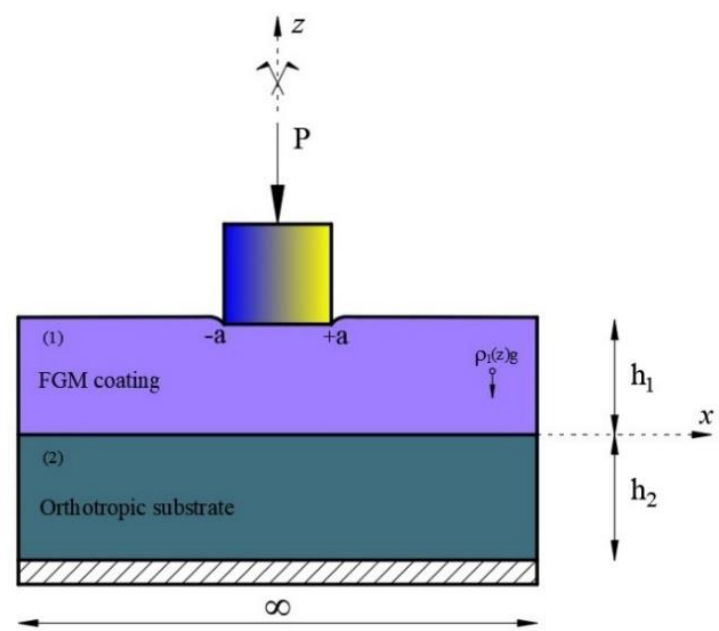

Fig. 1. Schematic sketch of the continuous contact problem between an FGM coating and orthotropic substrate indented by a rigid flat punch

where $\beta$ and $\Gamma$ can be any nonzero constants that control the variable speed of the shear modulus and density in the coating. Their products, $\beta \mathrm{h}_{1}$ and $\Gamma \mathrm{h}_{1}$, are known as the inhomogeneity parameters because they uniquely determine the distribution of shear modulus and density in the coating. The $\mathrm{x}$ axis is chosen to be the bottom surface of the coating so that the shear modulus and density remain continuous at the FGM coating-orthotropic substrate interface. $\mu_{0}$ and $\rho_{0}$ represent the shear modulus and density of the FGM coating on this interface.

For FGM coating, according to Hooke's law and the equilibrium equations in the absence of body forces, the following partial differential equations in terms of the displacement components $\mathrm{u}$ and $\mathrm{w}$ for plane strain state are obtained:

$$
\begin{aligned}
& \left(\kappa_{1}+1\right) u_{1 h, x x}+\beta\left(\kappa_{1}-1\right) u_{1 h, z}+\left(\kappa_{1}-1\right) u_{1 h, z z} \\
& +\beta\left(\kappa_{1}-1\right) w_{1 h, x}+2 w_{1 h, x z}=0 \\
& \left(\kappa_{1}+1\right) w_{1 h, z z}+\beta\left(3-\kappa_{1}\right) u_{1 h, x}+\left(\kappa_{1}-1\right) w_{1 h, x x} \\
& +\beta\left(\kappa_{1}+1\right) w_{1 h, z}+2 u_{1 h, x z}=0
\end{aligned}
$$

where a subscript after a comma designates a partial derivative. Subscript 1 refers to the FGM coating. The horizontal and vertical displacement components within the FGM coating are denoted by $\mathrm{u}$ and $\mathrm{w}$, respectively. The solution for the case with no body forces is denoted by the subscript $h . \kappa$ is the 
Kolosov's constant which can be calculated depending on Poisson's ratio $v$ for plane strain state by

$$
\kappa_{1}=3-4 v_{1}
$$

Define the Fourier's sine and cosine transforms as

$$
\begin{aligned}
& u_{1 h}(x, z)=\frac{2}{\pi} \int_{0}^{\infty} \phi_{1 h}(\alpha, z) \sin \alpha x d \alpha \\
& w_{1 h}(x, z)=\frac{2}{\pi} \int_{0}^{\infty} \psi_{1 h}(\alpha, z) \cos (\alpha x) d \alpha
\end{aligned}
$$

where $\alpha$ is the transform variable. Above Fourier's sine and cosine transforms are used to solve the partial differential equation system (3-4) reducing them to a system of ordinary differential equations. Employing the Fourier transforms to Eqs. (3-4) produces

$$
\begin{aligned}
& -\left(\kappa_{1}+1\right) \alpha^{2} \phi_{1 h}+\left(\kappa_{1}-1\right) \phi_{1 h, z z}-2 \alpha \psi_{1 h, z} \\
& +\beta\left(\kappa_{1}-1\right)\left[\phi_{1 h, z}-\alpha \psi_{1 h}\right]=0 \\
& -\left(\kappa_{1}-1\right) \alpha^{2} \psi_{1 h}+\left(\kappa_{1}+1\right) \psi_{1 h, z z}+2 \alpha \phi_{1 h, z} \\
& +\beta\left[\left(3-\kappa_{1}\right) \alpha \phi_{1 h}+\left(\kappa_{1}+1\right) \psi_{1 h, z}\right]=0
\end{aligned}
$$

After solving Eqs. (8-9) and using the corresponding inverse Fourier transforms, we find the displacement and stress fields for FGM coating in the form

$$
\begin{aligned}
& u_{1 h}(x, z)=\frac{2}{\pi} \int_{0}^{\infty} \sum_{j=1}^{4} A_{j} e^{\lambda_{j} z} \sin (\alpha x) d \alpha \\
& w_{1 h}(x, z)=\frac{2}{\pi} \int_{0}^{\infty} \sum_{j=1}^{4} A_{j} m_{j} e^{\lambda_{j} z} \cos (\alpha x) d \alpha \\
& \sigma_{1 x h}=\frac{2}{\pi} \int_{0}^{\infty} \sum_{j=1}^{4} \frac{\mu_{0}}{\left(\kappa_{1}-1\right)} A_{j} \chi_{j} e^{\left(\lambda_{j}+\beta\right) z} \cos (\alpha x) d \alpha
\end{aligned}
$$

$\sigma_{1 z h}=\frac{2}{\pi} \int_{0}^{\infty} \sum_{j=1}^{4} \frac{\mu_{0}}{\left(\kappa_{1}-1\right)} A_{j} \zeta_{j} e^{\left(\hat{\lambda}_{j}+\beta\right) z} \cos (\alpha x) d \alpha$

$$
\tau_{1 x z h}=\frac{2}{\pi} \int_{0}^{\infty} \sum_{j=1}^{4} \mu_{0} A_{j} \gamma_{j} e^{\left(\lambda_{j}+\beta\right) z} \sin (\alpha x) d \alpha
$$

where

$$
\begin{aligned}
& \lambda_{1}=\frac{1}{2}\left(-\beta-\sqrt{\frac{\left(4 \alpha^{2}+\beta^{2}\right)\left(1+\kappa_{1}\right)-4 \sqrt{\alpha^{2} \beta^{2}\left(-3-2 \kappa_{1}+\kappa_{1}^{2}\right)}}{1+\kappa_{1}}}\right) \\
& \lambda_{2}=\frac{1}{2}\left(-\beta+\sqrt{\frac{\left(4 \alpha^{2}+\beta^{2}\right)\left(1+\kappa_{1}\right)-4 \sqrt{\alpha^{2} \beta^{2}\left(-3-2 \kappa_{1}+\kappa_{1}^{2}\right)}}{1+\kappa_{1}}}\right) \\
& \lambda_{3}=\frac{1}{2}\left(-\beta-\sqrt{\frac{\left(4 \alpha^{2}+\beta^{2}\right)\left(1+\kappa_{1}\right)+4 \sqrt{\alpha^{2} \beta^{2}\left(-3-2 \kappa_{1}+\kappa_{1}^{2}\right)}}{1+\kappa_{1}}}\right) \\
& \lambda_{4}=\frac{1}{2}\left(-\beta+\sqrt{\frac{\left(4 \alpha^{2}+\beta^{2}\right)\left(1+\kappa_{1}\right)+4 \sqrt{\alpha^{2} \beta^{2}\left(-3-2 \kappa_{1}+\kappa_{1}^{2}\right)}}{1+\kappa_{1}}}\right)
\end{aligned}
$$




$$
m_{j}=\frac{\left(3 \beta+2 \lambda_{j}-\beta \kappa_{1}\right)\left(\lambda_{j}\left(\beta+n_{j}\right)\left(\kappa_{1}+1\right)-\alpha^{2}\left(\kappa_{1}+3\right)\right)}{\alpha\left(4 \alpha^{2}-\beta^{2}\left(\kappa_{1}-3\right)\left(\kappa_{1}+1\right)\right)}
$$

$\chi_{j}=\left(3-\kappa_{1}\right) m_{j} \lambda_{j}+\alpha\left(\kappa_{1}+1\right)$

$\zeta_{j}=\left(\kappa_{1}+1\right) m_{j} \AA_{j}+\alpha\left(3-\kappa_{1}\right)$

$$
\gamma_{j}=\lambda_{j}-\alpha m_{j} \quad(j=1, \ldots, 4)
$$

Using Hooke's law and the equilibrium equations in the existing body forces, the following partial differential equations in terms of the displacement components $\mathrm{u}_{1 \mathrm{p}}$ and $\mathrm{w}_{1 \mathrm{p}}$ for are obtained:

$$
\begin{aligned}
& \left(\kappa_{1}+1\right) u_{1 p, x x}+\beta\left(\kappa_{1}-1\right) u_{1 p, z}+\left(\kappa_{1}-1\right) u_{1 p, z z} \\
& +\beta\left(\kappa_{1}-1\right) w_{1 p, x}+2 w_{1 p, x z}=0 \\
& \left(\kappa_{1}+1\right) w_{1 p, z z}+\beta\left(3-\kappa_{1}\right) u_{1 p, x}+\left(\kappa_{1}-1\right) w_{1 p, x x} \\
& +\beta\left(\kappa_{1}+1\right) w_{1 p, z}+2 u_{1 p, x z}=\rho_{p} e^{(\Gamma-\beta) z}
\end{aligned}
$$

where subscript $\mathrm{p}$ represents the particular solution related to existing body forces. Also, $\rho_{\mathrm{p}}$ in Eq. (18) is defined as follows:

$\rho_{p}=\frac{\left(\kappa_{1}-1\right)}{\mu_{0}} \rho_{0} g$
For the particular solution, assuming displacement components $\mathrm{u}_{1 \mathrm{p}}=\mathrm{u}_{1} \mathrm{p}(\mathrm{x})$ and $\mathrm{w}_{1 \mathrm{p}}=$ $\mathrm{w}_{1} \mathrm{p}(\mathrm{z})$, Eqs. (17) and (18) yield

$$
\begin{aligned}
& \left(\kappa_{1}+1\right) u_{1 p, x x}=0 \\
& \left(\kappa_{1}+1\right) w_{1 p, z z}+\beta\left(3-\kappa_{1}\right) u_{1 p, x} \\
& +\beta\left(\kappa_{1}+1\right) w_{1 p, z}=\rho_{p} e^{(\Gamma-\beta) z}
\end{aligned}
$$

The solutions of Eqs. (20-21) are

$$
\begin{aligned}
u_{1 p}(x)= & K_{1} x+K_{2} \\
w_{1 p}(z) & =\frac{\left(\kappa_{1}-3\right) z}{\left(\kappa_{1}+1\right)} K_{1}-\frac{e^{-\beta z}}{\beta} L_{1} \\
& +L_{2}-\frac{e^{(\Gamma-\beta) z} \rho_{p}}{\left(\kappa_{1}+1\right)(\beta-\Gamma) \Gamma}
\end{aligned}
$$

When the displacement expressions $\mathrm{u}_{1 \mathrm{p}}$ and $\mathrm{w}_{1 \mathrm{p}}$ determined above are substituted in the constitutive equations known from the theory of elasticity, the stress components are obtained as follows: $\sigma_{1 z p}=\frac{\mu_{0}\left(\Gamma L_{1}\left(1+\kappa_{1}\right)+\mathrm{e}^{z \Gamma} \rho_{p}\right)}{\Gamma\left(-1+\kappa_{1}\right)}$

$\tau_{1 x z p}=0$

$\mathrm{K}_{1}, \mathrm{~K}_{2}, \mathrm{~L}_{1}, \mathrm{~L}_{2}$ in Eqs. (22-25) are the unknowns and they will be assigned applying the boundary conditions of the given below.

$$
\begin{aligned}
& u_{1 p}(0)=0 \\
& w_{1 p}(0)=0
\end{aligned}
$$

$$
\begin{aligned}
& \int_{0}^{h_{1}} \sigma_{1 x p} d z=0 \\
& \sigma_{1 z p}=\int_{z}^{h_{1}}-\rho_{0} g e^{\Gamma z} d z
\end{aligned}
$$

The coefficients obtained after the application of the above boundary conditions are given in the Appendix. The total displacement and stress components for FGM coating will be the 
superposition of two cases for the presence and absence of body forces.

$$
\begin{aligned}
& u_{1}(x, z)=u_{1 h}+u_{1 p} \\
& u_{1}(x, z)=u_{1 h}+u_{1 p} \\
& \sigma_{1 x}(x, z)=\sigma_{1 x h}+\sigma_{1 x p} \\
& \sigma_{1 z}(x, z)=\sigma_{1 z h}+\sigma_{1 z p}
\end{aligned}
$$

$$
\tau_{1 x z}(x, z)=\tau_{1 x z h}+\tau_{1 x z p}
$$

The constitutive relations for the plane strain orthotropy of a substrate can be reduced to the following matrix form:

$$
\left\{\begin{array}{c}
\sigma_{2 x} \\
\sigma_{2 y} \\
\sigma_{2 z} \\
\tau_{2 y z} \\
\tau_{2 x z} \\
\tau_{2 x y}
\end{array}\right\}=\left[\begin{array}{cccccc}
C_{11} & C_{12} & C_{13} & 0 & 0 & 0 \\
C_{21} & C_{22} & C_{23} & 0 & 0 & 0 \\
C_{31} & C_{32} & C_{33} & 0 & 0 & 0 \\
0 & 0 & 0 & C_{44} & 0 & 0 \\
0 & 0 & 0 & 0 & C_{55} & 0 \\
0 & 0 & 0 & 0 & 0 & C_{66}
\end{array}\right]\left\{\begin{array}{c}
\frac{\partial u_{2}}{\partial x} \\
0 \\
\frac{\partial w_{2}}{\partial z} \\
0 \\
\frac{\partial u_{2}}{\partial z}+\frac{\partial w_{2}}{\partial x} \\
0
\end{array}\right\}
$$

where $\sigma_{x}, \sigma_{y}, \sigma_{z}, \tau_{y z}, \tau_{x z}$ and $\tau_{x y}$ are the stress components; $\mathrm{u}$ and $\mathrm{w}$ are the displacement components. $\mathrm{C}_{\mathrm{ij}}$ denotes the stiffness coefficients for the orthotropic material. The subscript 2 refers to the orthotropic substrate.

When the constitutive relations are substituted into the stress equilibrium equations, two partial differential equations (PDEs) in terms of displacements are obtained, yielding the governing equations describing the elastic behavior of orthotropic materials.

$$
\begin{aligned}
& C_{11} u_{2, x x}+C_{55} u_{2, z z}+\left(C_{13}+C_{55}\right) w_{2, x z}=0 \\
& C_{55} w_{2, x x}+C_{33} w_{2, z z}+\left(C_{13}+C_{55}\right) u_{2, x z}=0
\end{aligned}
$$

Similar to the middle tiers for FGM coating, applying Fourier integral transform to Eqs. (34-35), we have

$$
\begin{aligned}
& -\alpha^{2} C_{11} \phi_{2}+C_{55} \phi_{2, z z}-\alpha\left(C_{13}+C_{55}\right) \psi_{2, z}=0 \\
& -\alpha^{2} C_{55} \psi_{2}+C_{33} \psi_{2, z z}+\alpha\left(C_{13}+C_{55}\right) \phi_{2, z}=0
\end{aligned}
$$

Solving Eqs. (36-37) gives the displacement and stress fields for the orthotropic substrate as follows:

$$
\begin{aligned}
u_{2}(x, z)= & \frac{2}{\pi} \int_{0}^{\infty} \sum_{i=1}^{4} B_{i} e^{\eta_{i} \alpha z} \sin (\alpha x) d \alpha \\
w_{2}(x, z)= & \frac{2}{\pi} \int_{0}^{\infty} \sum_{i=1}^{4} B_{i} \mho_{i} e^{\eta_{i} \alpha z} \cos (\alpha x) d \alpha \\
\sigma_{2 x}(x, z)= & \frac{2}{\pi} \int_{0}^{\infty} \alpha \sum_{i=1}^{4} B_{i}\left(C_{11}\right. \\
& \left.+C_{13} \sigma_{i} \eta_{i}\right) e^{\eta_{i} \alpha z} \cos (\alpha x) d \alpha
\end{aligned}
$$

$$
\begin{aligned}
\sigma_{2 z}(x, z) & =\frac{2}{\pi} \int_{0}^{\infty} \alpha \sum_{i=1}^{4} B_{i}\left(C_{13}\right. \\
& \left.+C_{33} \sigma_{i} \eta_{i}\right) e^{\eta_{i} \alpha z} \cos (\alpha x) d \alpha \\
\tau_{2 x z}(x, z) & =\frac{2}{\pi} \int_{0}^{\infty} \alpha \sum_{i=1}^{4} B_{i} C_{55}\left(\eta_{i}\right. \\
& \left.-\sigma_{i}\right) e^{\eta_{i} \alpha z} \sin (\alpha x) d \alpha
\end{aligned}
$$


where

$$
\begin{aligned}
& \eta_{1}=-\sqrt{-\frac{C_{13}{ }^{2}-C_{11} C_{33}+2 C_{13} C_{55}+\sqrt{\left(C_{13}{ }^{2}-C_{11} C_{33}\right)\left(C_{13}{ }^{2}-C_{11} C_{33}+4 C_{13} C_{55}+4 C_{55}{ }^{2}\right)}}{2 C_{33} C_{55}}} \\
& \eta_{2}=\sqrt{-\frac{C_{13}{ }^{2}-C_{11} C_{33}+2 C_{13} C_{55}+\sqrt{\left(C_{13}^{2}-C_{11} C_{33}\right)\left(C_{13}^{2}-C_{11} C_{33}+4 C_{13} C_{55}+4 C_{55}{ }^{2}\right)}}{2 C_{33} C_{55}}} \\
& \eta_{3}=-\sqrt{\frac{-C_{13}{ }^{2}+C_{11} C_{33}-2 C_{13} C_{55}+\sqrt{\left(C_{13}{ }^{2}-C_{11} C_{33}\right)\left(C_{13}{ }^{2}-C_{11} C_{33}+4 C_{13} C_{55}+4 C_{55}{ }^{2}\right)}}{2 C_{33} C_{55}}} \\
& \eta_{4}=\sqrt{\frac{-C_{13}{ }^{2}+C_{11} C_{33}-2 C_{13} C_{55}+\sqrt{\left(C_{13}^{2}-C_{11} C_{33}\right)\left(C_{13}{ }^{2}-C_{11} C_{33}+4 C_{13} C_{55}+4 C_{55}{ }^{2}\right)}}{2 C_{33} C_{55}}}
\end{aligned}
$$

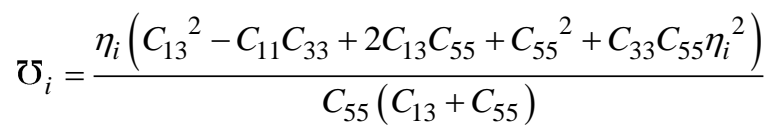

The coefficients $A_{i}$ and $B_{i},(i=1, \ldots, 4)$ in Eqs. $(10-14)$ and (28-32) are the unknowns, which will be determined from the boundary conditions of the contact problem which solution has to satisfy.

$$
\begin{aligned}
& \sigma_{1 z}\left(x, h_{1}\right)=\left\{\begin{array}{ll}
-p(x) & -a<x<a \\
0 & x \leq-a, \quad x \geq a
\end{array}\right\} \\
& \tau_{1 x z}\left(x, h_{1}\right)=0 \\
& \tau_{1 x z}(x, 0)=0 \\
& \tau_{2 x z}(x, 0)=0 \\
& \sigma_{1 z}(x, 0)=\sigma_{2 z}(x, 0) \\
& \frac{\partial}{\partial x}\left[w_{1}(x, 0)-w_{2}(x, 0)\right]=0 \\
& u_{2}\left(x,-h_{2}\right)=0 \\
& w_{2}\left(x,-h_{2}\right)=0
\end{aligned}
$$

where $p(x)$ is the unknown contact stress between the rigid flat punch and FGM coating on the contact boundary $(-\mathrm{a},+\mathrm{a})$.

\section{Deriving SIE, the normalization and numerical solution procedures of SIE}

Taking the Fourier transforms of the boundary conditions given by Eqs. (44) produces an algebraic equation system. Solving the equation system yields eight unknowns $A_{i}$ and $B_{i}(i=1, \ldots, 4)$ that appear in the stress and displacement fields. These unknowns may be determined in terms of the unknown contact stress. Notably, $A_{i}$ and $B_{i}$ are fairly long, and therefore, not presented here.

The problem is reduced to a SIE by using the punch profile displacement derivative condition (mixed condition), which is expressed for flat punch as follows:

$\frac{\partial w_{1}\left(x, h_{1}\right)}{\partial x}=0, \quad-a<x<+a$

By substituting the previously determined $A_{i}$ and $B_{i}$ coefficients into equation (45) and after some algebraic manupilations, the SIE is derived in the following form:

$$
\frac{1}{\pi} \int_{-\mathrm{a}}^{\mathrm{a}} p(t) d t\left[\frac{1}{t-x}+\varpi(x, t)\right]=0,-a<x+a
$$


where

$$
\begin{aligned}
& \varpi(x, t)=\frac{1}{\Lambda} \int_{0}^{\infty}\left(k_{1}(\alpha)-\Lambda\right) \sin \alpha(t-x) d \alpha, \\
& k_{1}(\alpha)=-\alpha \sum_{i=1}^{4} A_{i} m_{i} e^{\lambda_{i} h_{1}} \\
& \Lambda=\lim _{\alpha \rightarrow \infty} k_{1}(\alpha)
\end{aligned}
$$
that

Note that equilibrium of the rigid punch requires

$$
\int_{-a}^{+a} p(t) d t=P
$$

Note that when the value of press force exceeds $\mathrm{P}_{\mathrm{cr}}$, the interface separation takes place between the FGM coating and the orthotropic substrate. The continuous contact problem can only be solved if the pressing force is less than $\mathrm{P}_{\mathrm{cr}}$, which has yet to be determined. To determine the critical load factor and initial separation distance, the contact stress on the interface $\sigma_{z}(x, 0)$ should be evaluated first. Substituting the values of $A_{j}(j=1, \ldots, 4)$ as evaluated in terms of $\mathrm{p}(\mathrm{x})$ into (31), after some algebra the contact stress between the FGM coating and the orthotropic substrate can be found as

$$
\sigma_{1 z}(x, 0)=\frac{1}{\pi} \int_{-a}^{+a} p(t) \varphi(x, t) d t+\frac{\left(1-e^{\Gamma h_{1}}\right) \rho_{0} g}{\Gamma}
$$

where

$$
\begin{aligned}
& \varphi(x, t)=\int_{0}^{\infty} k_{2}(\alpha) \cos \alpha(t-x) d \alpha, \\
& k_{2}(\alpha)=\sum_{j=1}^{4} \frac{\mu_{0}}{\left(\kappa_{1}-1\right)} A_{j} \zeta_{j}
\end{aligned}
$$

To solve the SIE, the following normalizations are defined:

$$
s=\frac{x}{a}, \quad r=\frac{t}{a}, \quad \Upsilon(r)=\frac{p(r)}{P / h_{1}}
$$

Making use of the normalizations, the integral equation is rewritten as

$$
\frac{1}{\pi} \int_{-1}^{1} \Upsilon(r)\left[\frac{1}{r-s}+\varpi(s, r)\right] d r=0
$$

Equilibrium condition for the flat punch and the contact stress between FGM coating and orthotropic substrate are expressed in the form

$\frac{a}{h_{1}} \int_{-1}^{1} \Upsilon(r) d r=1$

$\frac{\sigma_{1 z}(x, 0)}{P / h_{1}}=\frac{1}{\pi} \int_{-1}^{1} \Upsilon(r) \varphi(s, r) d r+\frac{\left(1-e^{\Gamma h_{1}}\right)}{\Gamma h_{1}} \frac{1}{\lambda}$

where $\lambda$ is the load factor and is defined as:

$\lambda=\frac{P}{\rho_{0} g h_{1}^{2}}$

Through the use of Gauss-Chebyshev integration formulas, Erdogan and Gupta [41] successfully tackled two kinds of SIEs. Due to the existence of singularities of the unknown stress function at both limits of the integral, the singularity index of the integral equation (52) is +1 , and the numerical solution of the singular integral equation can be found as follows

$$
\Upsilon(r)=\vartheta(r)\left(1-r^{2}\right)^{-1 / 2}
$$

Based on these observations, we have for an integral equation, equilibrium condition, and contact stress between FGM coating and orthotropic substrate, respectively as follows:

$$
\sum_{i=1}^{n} W_{i}\left[\frac{1}{r_{i}-s_{j}}+\varpi\left(s_{j}, r_{i}\right)\right] \vartheta\left(r_{i}\right)=0,
$$

$$
\frac{a}{h_{1}} \sum_{i=1}^{n} W_{i} \vartheta\left(r_{i}\right)=1
$$




$$
\begin{aligned}
\frac{\sigma_{1 z}(x, 0)}{P / h_{1}} & =\frac{a}{h_{1}} \sum_{i=1}^{n} W_{i} \varphi\left(s_{j}, r_{i}\right) \vartheta\left(r_{i}\right) \\
& +\frac{\left(1-e^{\Gamma h_{1}}\right)}{\Gamma h_{1}} \frac{1}{\lambda}
\end{aligned}
$$

where

$$
\begin{aligned}
& W_{1}=W_{n}=\frac{\pi}{2(n-1)}, \\
& W_{i}=\frac{\pi}{n-1}(i=2, \ldots, n-1) \\
& r_{i}=\cos \left(\frac{i-1}{n-1} \pi\right) \quad(i=1, \ldots, n) \\
& s_{j}=\cos \left(\frac{2 j-1}{2 n-2} \pi\right) \quad(j=1, \ldots, n-1)
\end{aligned}
$$

The algebraic system (57-58) contains $n$ equations for the determination of $\mathrm{n}$ unknowns, i.e., the contact stress $\vartheta\left(r_{i}\right)$. The unknowns $\vartheta\left(r_{i}\right)$, (i= $1, \ldots, n)$ are determined from this algebraic system. By using (56), substituting the results into (59), the contact stress is evaluated. It should be noted that the integral equation (52) is valid if the contact stress obtained from (54) is compressive everywhere. By varying the load factor $\lambda$ and evaluating the contact stress for a given value of $\mathrm{a} / \mathrm{h}_{1}$, one can easily determine both the location $\mathrm{x}_{\mathrm{cr}}$ at which the interface separation begins and the corresponding critical load factor $\lambda_{\text {cr. }}$ This factor is related to the initial separation load $\mathrm{P}_{\mathrm{cr}}$, by

$\lambda_{c r}=\frac{P_{c r}}{\rho_{0} g h_{1}^{2}}$

\section{Results and discussion}

In this section, the numerical results of the continuous contact problem based on the above analysis will be discussed in detail. The materials used for the orthotropic substrate are given in Table 1.

First of all, it is aimed to verify the results by comparing the present study and some special cases of the present study available in the literature. Tables 2-5 contain some numerical values related to this comparing. The FGM coating was transformed into a homogeneous isotropic layer in this context by bringing the material inhomogeneity parameter value closer to zero (by giving a value very close to zero, that is, $\left.\beta h_{1} \rightarrow 0\right)$. The $h_{2}$ height was set to be very large $\left(h_{2} \rightarrow \infty\right)$, and the substrate was transformed into a half-plane. If the $\mathrm{h}_{2 \mathrm{re}}$ height is set too low $\left(\mathrm{h}_{2} \rightarrow 0\right)$, a transition to the monolayer problem supported on a rigid foundation is provided. If the $\mathrm{a} / \mathrm{h}_{1}$ normalized punch length is chosen too small $\left(\mathrm{a} / \mathrm{h}_{1} \rightarrow 0\right)$, the special case that is pressed with a single load is provided. To transform the orthotropic substrate into an isotropic one, the elastic constants were determined using the Eqs. (62).

$$
\begin{aligned}
& C_{11}=C_{33}=\frac{\left(1+\kappa_{2}\right) \mu_{2}}{\kappa_{2}-1} \\
& C_{13}=\frac{\left(3-\kappa_{2}\right) \mu_{2}}{\kappa_{2}-1} \\
& C_{55}=\mu_{2}
\end{aligned}
$$

Table 1. Mechanical properties of the orthotropic materials used for the substrate in the study [42-44]

\begin{tabular}{cccc}
\hline \multirow{2}{*}{ Mechanical Property } & \multicolumn{3}{c}{ Orthotropic Material } \\
\cline { 2 - 4 } & $\begin{array}{c}\text { Material 1 } \\
\text { (Carbon/Epoxy) }\end{array}$ & $\begin{array}{c}\text { Material 2 } \\
\text { (Glass/Vinylester) }\end{array}$ & $\begin{array}{c}\text { Material 3 } \\
\text { (Boron/Aluminum) }\end{array}$ \\
\hline $\mathrm{E}_{\mathrm{x}}(\mathrm{GPa})$ & 157.9 & 19.268 & 227.5 \\
$\mathrm{E}_{\mathrm{y}}(\mathrm{GPa})$ & 9.584 & 13.210 & 137.9 \\
$\mathrm{E}_{\mathrm{z}}(\mathrm{GPa})$ & 9.584 & 13.210 & 137.9 \\
$\mu_{\mathrm{xy}}(\mathrm{GPa})$ & 5.930 & 4.572 & 55.152 \\
$\mu_{\mathrm{xz}}(\mathrm{GPa})$ & 5.930 & 4.572 & 55.152 \\
$\mu_{\mathrm{yz}}(\mathrm{GPa})$ & 3.227 & 3.7 & 49.244 \\
$v_{\mathrm{xy}}$ & 0.32 & 0.31 & 0.24 \\
$v_{\mathrm{xz}}$ & 0.32 & 0.31 & 0.24 \\
$v_{\mathrm{yz}}$ & 0.49 & 0.35 & 0.40 \\
\hline
\end{tabular}


Table 2. Comparison of the results of the present study with the results in Çakıroğlu [45], which is a special case of the present study $\left(\left(1+\kappa_{2}\right) \mu_{1} /\left(1+\kappa_{1}\right) \mu_{2}=1, \mathrm{~h}_{2} \rightarrow \infty\right)$

\begin{tabular}{ccccc}
\hline \multirow{2}{*}{$\mathrm{a} / \mathrm{h}_{1}$} & \multicolumn{2}{c}{ Present Study } & \multicolumn{2}{c}{ Çakıroğlu [45] } \\
\cline { 2 - 5 } & $\lambda_{\mathrm{cr}}$ & $\mathrm{X}_{\mathrm{cr}} / \mathrm{h}_{1}$ & $\lambda_{\mathrm{cr}}$ & $\mathrm{X}_{\mathrm{cr}} / \mathrm{h}_{1}$ \\
\hline 0.5 & 158.352 & 3.07 & 158.305 & 3.074 \\
1 & 209.868 & 3.51 & 209.738 & 3.506 \\
2 & 325.994 & 4.53 & 325.881 & 4.532 \\
\hline
\end{tabular}

Table 3. Comparison of the results of the present study with the results in Geçit [46], which is a special case of the present study $\left(\mathrm{a} / \mathrm{h}_{1} \rightarrow 0, \mathrm{~h}_{2} \rightarrow \infty\right)$

\begin{tabular}{|c|c|c|c|c|}
\hline \multirow{2}{*}{$\frac{\left(1+\kappa_{2}\right)}{\left(1+\kappa_{1}\right)} \frac{\mu_{1}}{\mu_{2}}$} & \multicolumn{2}{|c|}{ Present Study } & \multicolumn{2}{|c|}{ Geçit [46] } \\
\hline & $\lambda_{\mathrm{cr}}$ & $\mathrm{x}_{\mathrm{cr}} / \mathrm{h}_{1}$ & $\lambda_{\mathrm{cr}}$ & $\mathrm{x}_{\mathrm{cr}} / \mathrm{h}_{1}$ \\
\hline 0.1 & 55.0893 & 1.89 & 56.42 & 1.86 \\
\hline 1 & 139.042 & 2.90 & 140.39 & 2.94 \\
\hline
\end{tabular}

Table 4. Comparison of the results of the present study with the results in Civelek and Erdogan [47], which is a special case of the present study $\left(\mathrm{h}_{2} \rightarrow 0\right)$

\begin{tabular}{ccccc}
\hline \multirow{2}{*}{$\mathrm{a} / \mathrm{h}_{1}$} & \multicolumn{2}{c}{ Present Study } & \multicolumn{2}{c}{ Civelek and Erdogan [47] } \\
\cline { 2 - 5 } & $\lambda_{\mathrm{cr}}$ & $\mathrm{x}_{\mathrm{cr}} / \mathrm{h}_{1}$ & $\lambda_{\mathrm{cr}}$ & $\mathrm{x}_{\mathrm{cr}} / \mathrm{h}_{1}$ \\
\hline$\rightarrow 0$ & 44.136 & 1.77 & 44.13924 & 1.77055 \\
\hline
\end{tabular}

Table 5. Comparison of the results of the present study with the results in Civelek et al. [48], which is a special case of the present study $\left(\mathrm{h}_{2} \rightarrow 0\right)$

\begin{tabular}{ccc}
\hline $\mathrm{a} / \mathrm{h}_{1}$ & Present Study & Civelek et al. [48] \\
\cline { 2 - 3 } & $\lambda_{\text {cr }}$ & $\lambda_{\text {cr }}$ \\
\hline 0.5 & 58.8567 & 58.88 \\
1 & 92.3691 & 92.40 \\
2 & 171.052 & 169.57 \\
\hline
\end{tabular}

First, by performing the relevant transformations mentioned above, the results of the continuous contact of the homogeneous isotropic layer and the homogeneous isotropic half-plane pressed with the rigid flat punch, which is a special case of this study and previously studied by Çakıroğlu [45], were obtained. The obtained results were compared to Çakıroğlu [45], and the accuracy of the results was verified. As a result of the comparison, it was determined that the results were quite compatible with one another (see Table 2). This validated the accuracy of the current study's findings.

The second comparison is the comparison made with Geçit [46], who worked on this problem before, by transitioning to the contact problem between the homogeneous layer loaded with a single load and the homogeneous half-plane, which is also a special case of this study. The comparison results are given in Table 3 and the compatibility of the results is once again demonstrated.

The results of another special case of this problem, the continuous contact problem of the homogeneous isotropic layer resting on a rigid foundation and loaded with a single load, were obtained using the above-mentioned transformations and compared with Civelek and Erdogan [47]. (see Table 4). This comparison also showed the accuracy of the results of the current study as a result of the agreement between the two studies.

The final comparison made to verify the accuracy of the results of the study is given in Table 5. The FGM coating was converted into a homogeneous isotropic layer, and the orthotropic substrate's height was chosen to be very small, and 
the problem was matched with the continuous contact problem of the homogeneous isotropic layer resting on a rigid foundation and pressed with a rigid flat punch. The obtained results were compared with the previously discussed study by Civelek et al. [48], and it was discovered that the results were quite close to each other. Thus, verification of the present analytical procedure is provided by the comparison.

In Figs. 2-5, the changes of the normalized contact stress distributions occurring at the punchFGM coating interface, depending on the normalized punch length, inhomogeneity parameter, material type of orthotropic substrate, and dimensionless press force are given, respectively. The normalized contact stresses, as shown in the figures, go to infinity under the sharp edges of the punch and take minimum values on the axis of symmetry or near the axis of symmetry. When the integral equation is examined, the sharp edges of the punch are expected to be singular points for stresses.

Distributions of the normalized contact stress along the punch-FGM coating interface are illustrated in Fig. 2 considering different values of the normalized punch length. As shown in the figure, as the punch length increases, the force spreads over a larger area and the normalized contact stresses at this interface decrease.

In Fig. 3, the effect of the inhomogeneity parameter $\beta h_{1}$ on the normalized contact stress at the punch-FGM coating interface is presented. Using Eq. (1), it is possible to conclude that changing h1 changes the stiffness of the FGM coating in the $\mathrm{z}$ directions. The stiffness of the upper surface of the FGM coating is greater than that of the lower surface at positive values of $h_{1}$. When $h_{1}$ is negative, the stiffness of the FGM coating on the lower surface is greater than on the upper surface.

For instance, if $\beta h_{1}$ is equal to 0.6931 , the stiffness of the top surface of the FGM coating is approximately two times greater than the stiffness of the lower surface of the FGM coating. If $\beta \mathrm{h}_{1}$ equals -1.6094 , the stiffness of the upper surface of the FGM coating is approximately five times that of the lower surface of the FGM coating.

When Fig. 3 is examined, as $\beta \mathrm{h}_{1}$ values increase, or in other words, as the stiffness on the upper surface of the FGM coating is increased compared to the stiffness on the lower surface, an increase is observed in the stresses at the corners of the punch, while the normalized contact stress values decrease toward the middle of the punch.

Fig. 4 depicts the normalized contact stress distributions along with the punch-FGM coating interface for different material types used for the orthotropic substrate. The direct effect of stiffness in the direction of the pressing force is striking when orthotropic materials are examined. When the material types are compared, it is clear that the stiffness increases from Material 1 to Material 3 in the direction of the pressing force (loading direction). When using an orthotropic substrate that is more rigid in the direction of loading, the normalized contact stress values under the punch increase toward the punch's center and decreases toward the punch's edges.

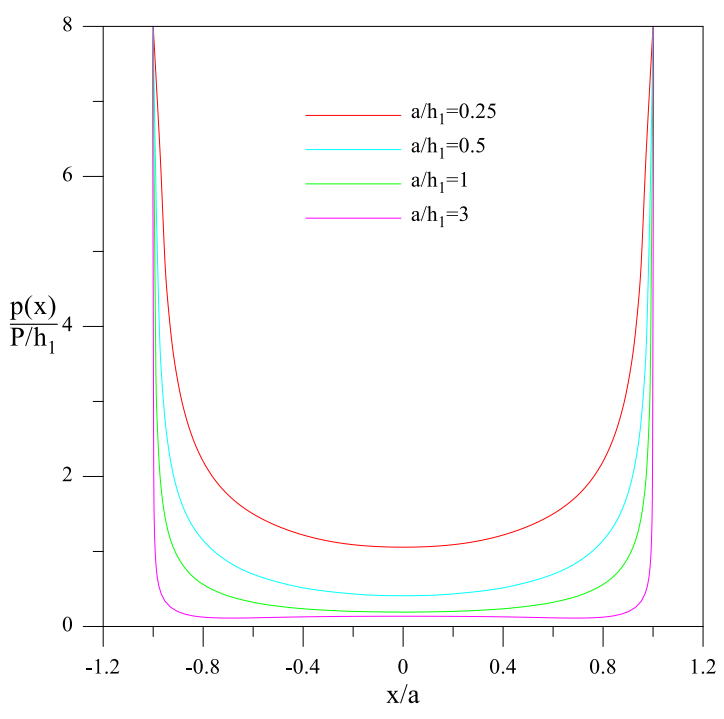

Fig. 2. The effect of normalized punch length on normalized contact stress distribution under punch $\left(\beta h_{1}=0.6931, \kappa_{1}=1.84, \mu_{0}=17\right.$, Material $\left.1, h_{1} / h_{2}=1\right)$ 


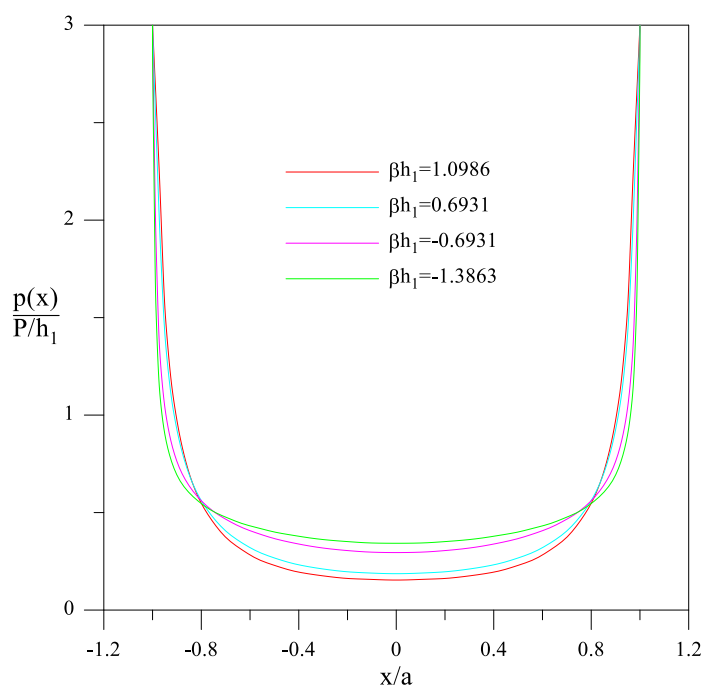

Fig. 3. The effect of inhomogeneity parameter on normalized contact stress distribution under punch $\left(\mathrm{a} / \mathrm{h}_{1}=1, \kappa_{1}=1.84, \mu_{0}=17\right.$, Material $\left.2, \mathrm{~h}_{1} / \mathrm{h}_{2}=1\right)$

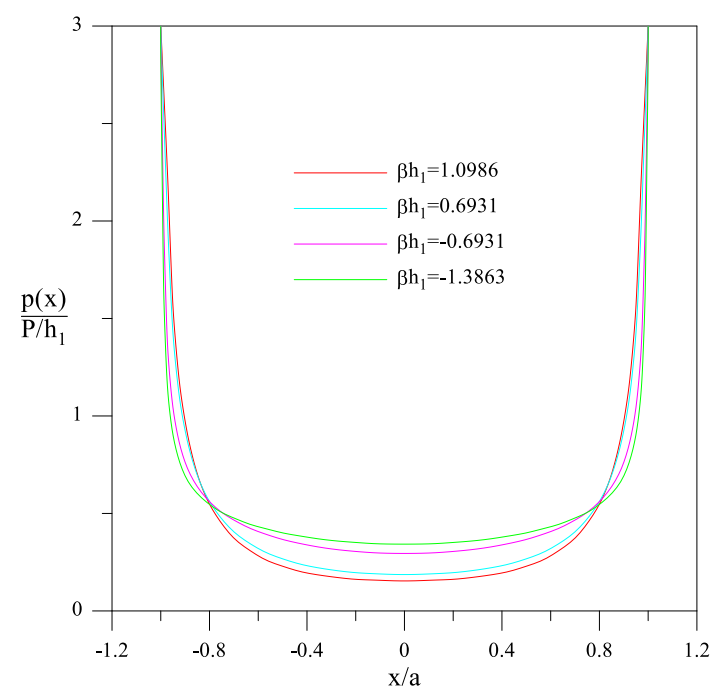

Fig. 3. The effect of inhomogeneity parameter on normalized contact stress distribution under punch $\left(\mathrm{a} / \mathrm{h}_{1}=1, \kappa_{1}=1.84, \mu_{0}=17\right.$, Material $\left.2, \mathrm{~h}_{1} / \mathrm{h}_{2}=1\right)$

The effect of the dimensionless press force on the normalized contact stress distributions under punch is depicted in Fig. 5. Note that $\mathrm{P} /\left(\mu_{0} \mathrm{~h}_{1}\right)$ varies between 0.01 and 0.1 . As $\mathrm{P} /\left(\mu_{0} \mathrm{~h}_{1}\right)$ increases, the values of the normalized contact stress increase because of the increase in the net pressure on the contact surface.

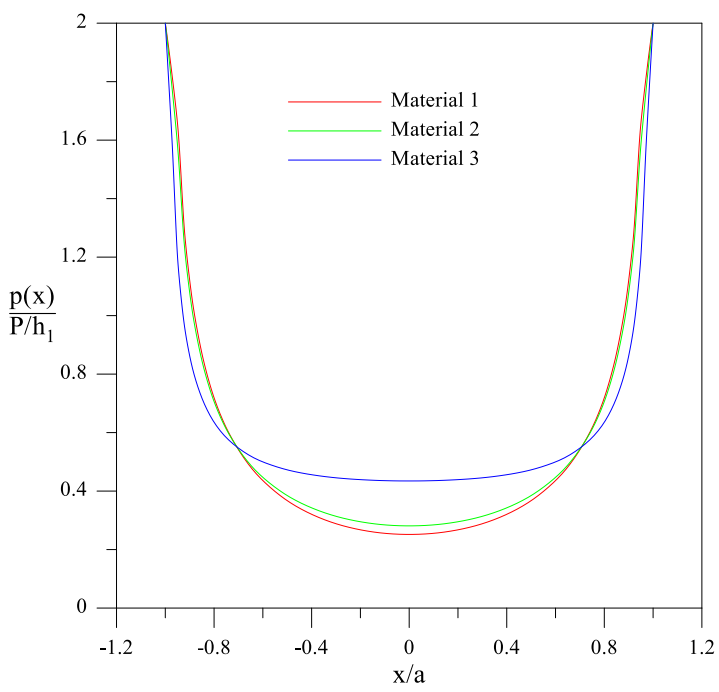

Fig. 4. The effect of orthotropic material type on normalized contact stress distribution under punch $\left(\mathrm{a} / \mathrm{h}_{1}=0.8, \beta \mathrm{h}_{1}=0.4055, \kappa_{1}=1.84, \mu_{0}=17, \mathrm{~h}_{1} / \mathrm{h}_{2}=1\right)$

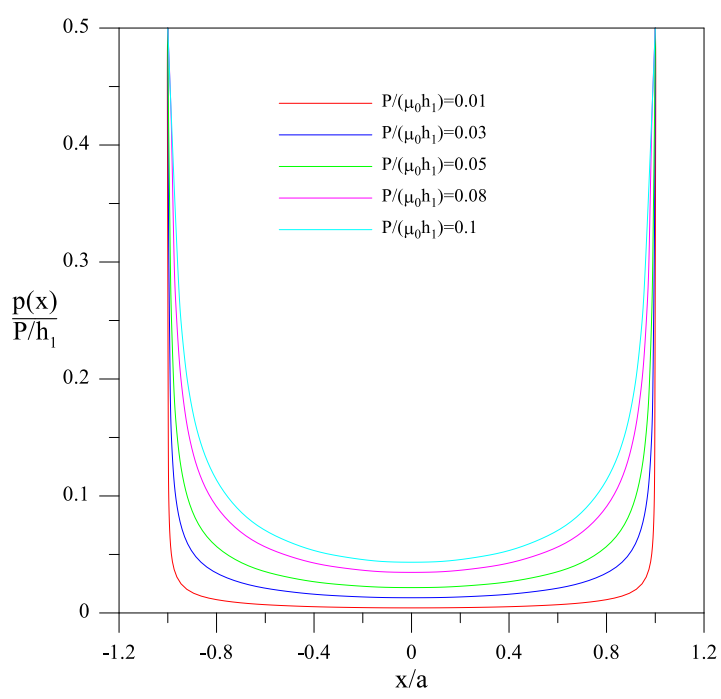

Fig. 5. The effect of dimensionless press force on normalized contact stress distribution under punch $\left(\mathrm{a} / \mathrm{h}_{1}=0.5, \beta \mathrm{h}_{1}=0.6931\right.$, Material $\left.2, \mathrm{~h}_{1} / \mathrm{h}_{2}=1\right)$

In Figs. 6-9, the effects of variation of normalized punch length, inhomogeneity parameters, and orthotropic substrate material type on the normalized contact stress distributions at the interface of FGM coating and orthotropic substrate are presented. In the case of continuous contact, two regions emerge, as shown in the figures. 


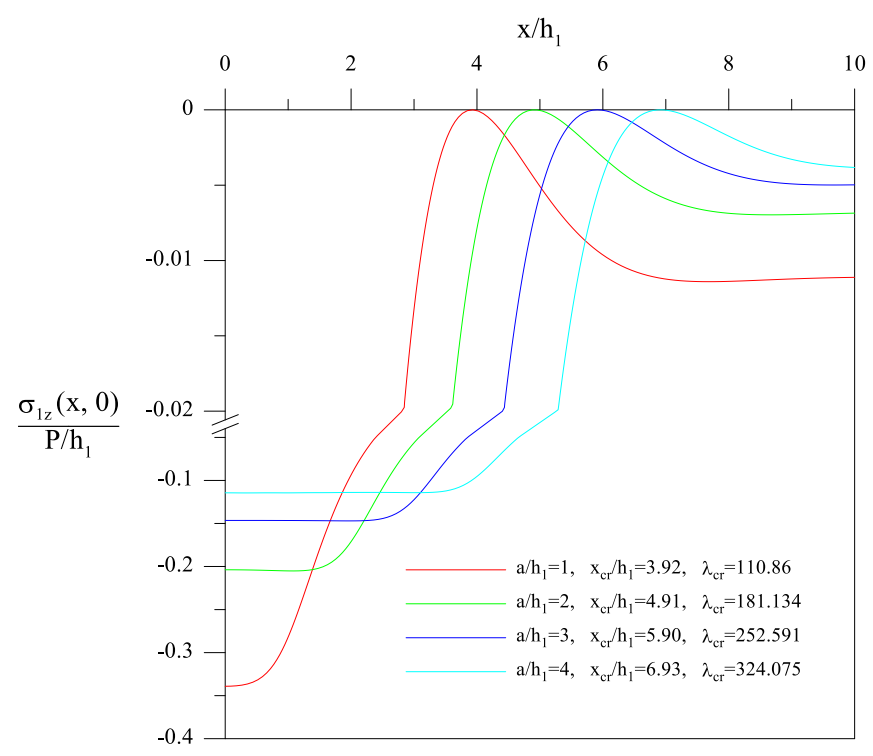

Fig. 6. Normalized contact stress distributions on the contact surface between the FGM coating and the orthotropic substrate for various values of normalized punch length $\left(\beta h_{1}=0.6931, \Gamma h_{1}=0.4055, \kappa_{1}=1.84, \mu_{0}=17\right.$, Material 2, $\left.\mathrm{h}_{1} / \mathrm{h}_{2}=1\right)$

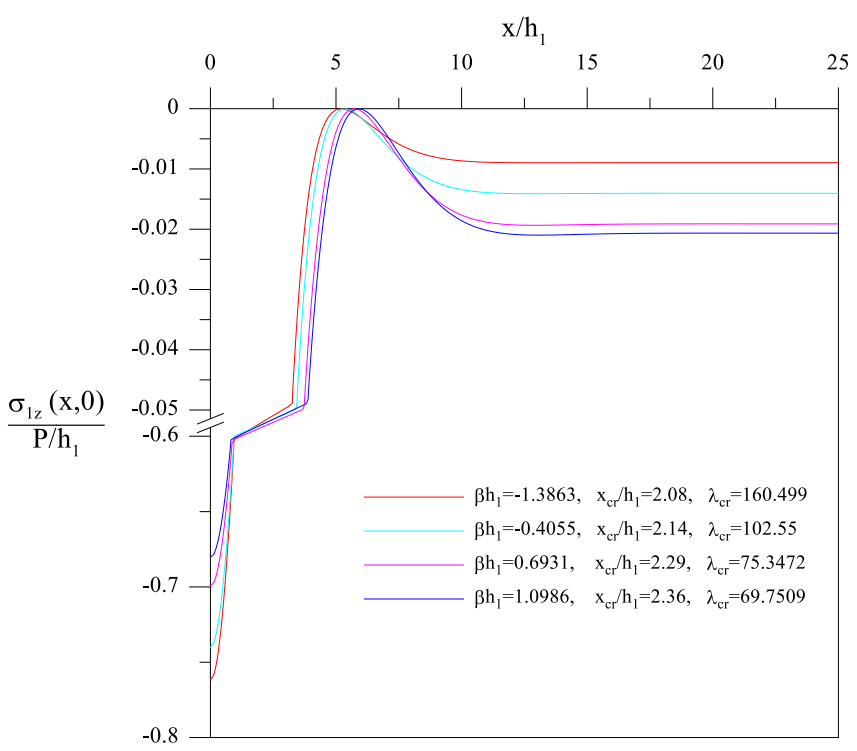

Fig. 7. Normalized contact stress distributions on the contact surface between the FGM coating and the orthotropic substrate for various values of inhomogeneity parameter $\beta \mathrm{h}_{1}\left(\mathrm{a} / \mathrm{h}_{1}=0.4, \Gamma \mathrm{h}_{1}=0.6931, \kappa_{1}=1.84, \mu_{0}=17\right.$, Material 3, $\left.\mathrm{h}_{1} / \mathrm{h}_{2}=1\right)$ 


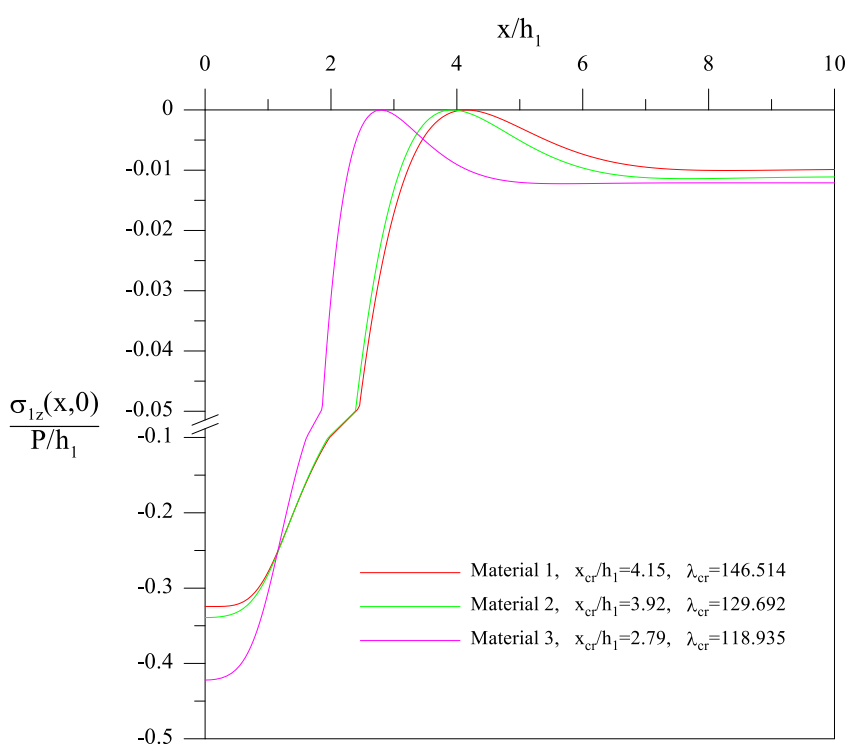

Fig. 8. Normalized contact stress distributions on the contact surface between the FGM coating and the orthotropic substrate for various orthotropic materials $\left(\mathrm{a} / \mathrm{h}_{1}=1, \beta \mathrm{h}_{1}=0.6931, \Gamma \mathrm{h}_{1}=0.6931, \kappa_{1}=1.84, \mu_{0}=17, \mathrm{~h}_{1} / \mathrm{h}_{2}=1\right)$

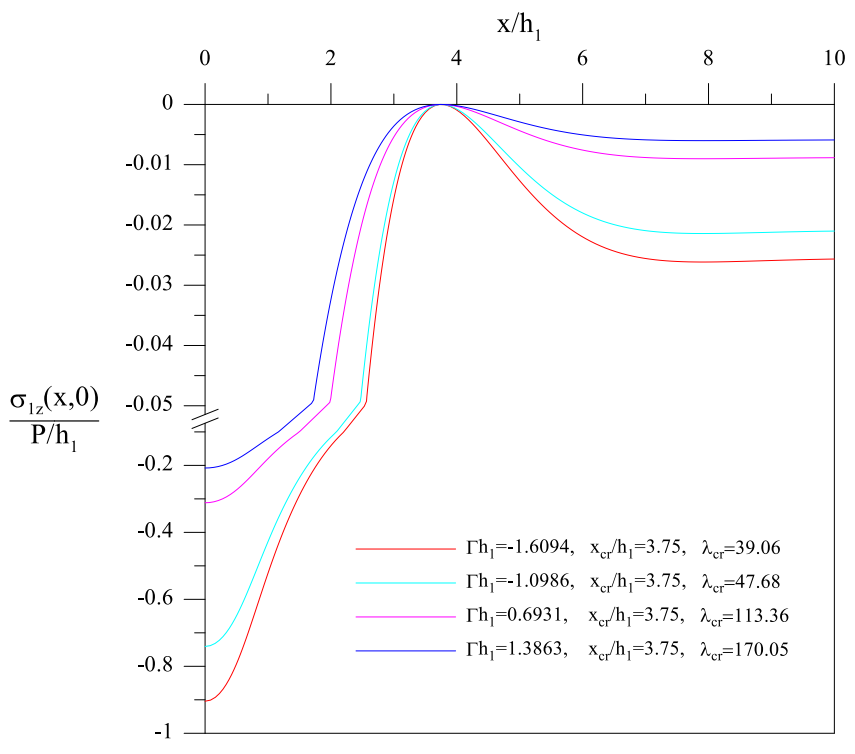

Fig. 9. Normalized contact stress distributions on the contact surface between the FGM coating and the orthotropic substrate for various values of inhomogeneity parameter $\Gamma \mathrm{h}_{1}\left(\mathrm{a} / \mathrm{h}_{1}=0.5, \beta \mathrm{h}_{1}=0.6931, \kappa_{1}=1.84, \mu_{0}=17\right.$, Material 1 ,

$$
\left.\mathrm{h}_{1} / \mathrm{h}_{2}=1\right)
$$

The first is the contact zone where the pressing force has a large effect, and the second is the contact zone where the press force's effect decreases and disappears. The normalized contact stresses reach their maximum value in the contact region where the pressing force is affected, and these points form the contact stress peaks. Only the effect of the FGM coating's body force emerges in the contact region where the effect of the pressing force disappears, and the contact stresses in this region are equivalent to the body forces. Fig. 6 shows the variation of critical load factor and initial separation distance depending on the normalized punch length. As seen in the figure, as the normalized punch length 
increases, the critical load factor increases. Separations between the FGM coating and the orthotropic substrate will be more difficult as a result of this. Another conclusion from the graph is that increasing the normalized punch length shifts the initial separation distance away from the symmetry axis.

In Fig. 7, the effect of inhomogeneity parameter $\beta \mathrm{h}_{1}$ change on the critical load factor and initial separation distance between FGM coating and the orthotropic substrate is illustrated. The figure shows that as the inhomogeneity parameter value increases, that is, as the rigidity of the upper surface of the FGM coating increases in comparison to the lower surface, the critical load factor value decreases while the initial separation distance increases. This result indicates that the increase in the relevant parameter value makes the separations easier, and the position of the initial separation moves away from the symmetry axis.

Fig. 8 depicts the effect of the material type used for the orthotropic substrate on the critical load factor and initial separation distance at the interface of FGM coating and orthotropic substrate. As given in Table 1, Young's modulus in $-\mathrm{z}$ direction which is the loading direction is the highest for Material 3. The lowest critical load factor value can be seen in the figure when this orthotropic material is used. FGM coating is separated from the orthotropic substrate with less load effect, that is, more easily, as the orthotropic material becomes more rigid in the direction of loading. Another conclusion to be drawn from the graph is that using a more rigid orthotropic substrate in the loading direction brings the initial separation distance closer to the axis of symmetry.

The variations of the critical load factor and the initial separation distance for different values of the inhomogeneity parameter $\Gamma \mathrm{h}_{1}$ are displayed in Fig. 9. An increase in the value of this parameter with a positive sign indicates that the density of the FGM coating's upper surface is greater than that of the lower surface. Increasing the aforementioned parameter's absolute value with a negative sign represents the inverse of this situation. As the density of the FGM coating increases from the lower surface to the upper surface, the FGM coating becomes heavier, which, as expected, makes the separation at the interface of the FGM coating and the orthotropic substrate more difficult. An interesting result that emerges from the figure is that the inhomogeneity parameter $\Gamma h_{1}$ has no effect on the initial separation distance at the mentioned interface.

\section{Conclusions}

In this study, elastostatic contact mechanics analysis between the FGM coating which is pressed by a rigid flat punch, and the orthotropic substrate is performed. The formulation of the contact problem is carried out considering the general theory of elasticity. Constitutive relations of the plane elasticity are utilized under the plane strain deformation case. The governing PDEs for the elastostatic contact problem are derived. The Fourier sine and cosine transformations are used to solve these PDEs analytically. The unknown functions that appear in the displacement fields for the FGM coating and orthotropic substrate are determined by applying boundary conditions, and the mixed boundary value problem is reduced to a SIE. The SIE is solved numerically using GaussChebyshev integration formulas. Some essential conclusions drawn from the study are provided as follows:

$>$ While increasing the normalized punch length reduces the normalized contact stresses under the punch, it increases the critical load factor and initial separation distance at the interface of FGM coating and orthotropic substrate.

$>$ The increase in the dimensionless press force causes an increase in the normalized contact stress values under the punch.

$>$ As the upper surface of the FGM coating becomes rigid relative to the lower surface, the minimum value of the contact stress under the punch decreases. This change in FGM coating stiffness facilitates separation at the contact surface with the orthotropic substrate and shifts the first separation point away from the symmetry axis. As the value of the inhomogeneity parameter $\Gamma h_{1}$ increases, that is, 
the heavier the FGM coating, the greater press force is required for the separation at the interface with the orthotropic substrate. The change of this parameter does not affect the initial separation distance.

For the orthotropic substrate, the value of Young's modulus in the loading direction is important. The normalized contact stress values under the punch tend to increase toward the center of the punch and decrease toward the edges of the punch as Young's modulus value in this direction increases, that is, as the stiffness of the substrate increases in the direction of loading.

$>$ The most difficult separation that will occur at the interface of the orthotropic substrate and the FGM coating occurs when Material 1 is used.

$>$ The present work provided the theoretical basis for the design of the FGM coating-orthotropic substrate system.

\section{Declaration of conflicting interests}

The author(s) declared no potential conflicts of interest with respect to the research, authorship, and/or publication of this article.

\section{References}

[1] Hertz H (1882) Über die Berührung fester elastischer Körper. J Rein Angew Math 92:156171.

[2] Boussinesq J (1885) Application des Potentiels a L'etude de L'Equilibre et du Mouvement des Solides Elastiques. Gauthier-Villars, Paris.

[3] Popov VL, Heß M, Willert E (2019) Handbook of contact mechanics: exact solutions of axisymmetric contact problems. Springer. Nature.

[4] Keer LM, Dundurs J, Tsai KC (1972) Problems involving a receding contact between a layer and a half space. J Appl Mech 39:1115-1120.

[5] Weitsman Y (1972) A tensionless contact between a beam and an elastic half-space. Int J Eng Sci 10:73-81.

[6] Nowell D, Hills DA (1988) Contact problems incorporating elastic layers. Int J Solids Struct 24:105-115.

[7] Birinci A, Erdol R (2001) Continuous and discontinuous contact problem for a layered composite resting on simple supports. Struct Eng Mech 12:17-34.

[8] Comez I, Birinci A, Erdol R (2004) Double receding contact problem for a rigid stamp and two elastic layers. Eur J Mech A Solids 23:301-309.

[9] Ozsahin TS (2007) Frictionless contact problem for a layer on an elastic half plane loaded by means of two dissimilar rigid punches. Struct Eng Mech 25:383-403.

[10] Ciulcu C, Hoarau-Mante T-V, Sofonea M (2002) Viscoelastic sliding contact problems with wear. Math Comput Modell 36:861-874.

[11] Guler MA (2014) Closed-form solution of the twodimensional sliding frictional contact problem for an orthotropic medium. Int J Mech Sci 87:72-88.

[12] Ballard P (2013) Steady sliding frictional contact problems in linear elasticity. J Elast 110:33-61.

[13] Hills DA, Ramesh R, Barber JR, Moore MR (2018) Methods to solve half-plane partial slip contact problems. Int J Solids Struct 155:155-159.

[14] Wang ZJ, Wang WZ, Wang H, Zhu D, Hu YZ (2010) Partial slip contact analysis on threedimensional elastic layered half space. J Tribol 132.

[15] Pauk V, Zastrau B (2002) 2D rolling contact problem involving frictional heating. Int J Mech Sci 44:2573-2584.

[16] González JA, Abascal R (2000) An algorithm to solve coupled 2D rolling contact problems. Int J Numer Meth Eng 49:1143-1167.

[17] Guler MA, Adibnazari S, Alinia Y (2012) Tractive rolling contact mechanics of graded coatings. Int $\mathrm{J}$ Solids Struct 49:929-945.

[18] Zozulya VV (2019) Solution of the elastodynamic contact problem for a cracked body using the boundary integral equation method. Mech Adv Mater Struct 26:924-937.

[19] Mijar AR, Arora JS (2000) Review of formulations for elastostatic frictional contact problems. Struct Multidisc Optim 20:167-189.

[20] Jang YH, Cho H, Barber JR (2009) The thermoelastic Hertzian contact problem. Int $\mathrm{J}$ Solids Struct 46:4073-4078.

[21] Liu TJ, Wang YS, Zhang C (2008) Axisymmetric frictionless contact of functionally graded materials. Arch Appl Mech 78:267-282.

[22] Ke LL, Wang YS (2006) Two-dimensional contact mechanics of functionally graded materials with arbitrary spatial variations of material properties. Int J Solids Struct 43:5779-5798.

[23] Öner E, Adiyaman G, Birinci A (2017) Continuous contact problem of a functionally graded layer 
resting on an elastic half-plane. Arch Mech 69:5373.

[24] Öner E, Birinci A (2020) Investigation of the solution for discontinuous contact problem between a functionally graded (FG) layer and homogeneous half-space. Arch Appl Mech 90:2799-2819.

[25] Arslan O (2020) Plane contact problem between a rigid punch and a bidirectional functionally graded medium. Eur J Mech A/Solids 80:103925.

[26] Willis JR (1966) Hertzian contact of anisotropic bodies. J Mech Phys Solids 14:163-176.

[27] Urquhart EE, Pindera MJ (1994) Incipient separation between a frictionless flat punch and an anisotropic multilayered half plane. Int J Solids Struct 31:2445-2461.

[28] Lin Y, Ovaert TC (2004) A rough surface contact model for general anisotropic materials. J Tribol 126:41-49.

[29] Kahya V, Ozsahin TS, Birinci A, Erdol R (2007) A receding contact problem for an anisotropic elastic medium consisting of a layer and a half plane. Int J Solids Struct 44:5695-5710.

[30] Migórski S, Ochal A, Sofonea M (2011) Analysis of a quasistatic contact problem for piezoelectric materials. J Math Anal Appl 382:701-713.

[31] Bagault C, Nélias D, Baietto MC, Ovaert TC (2013) Contact analyses for anisotropic half-space coated with an anisotropic layer: effect of the anisotropy on the pressure distribution and contact area. Int J Solids Struct 50:743-754.

[32] Li X-Y, Zheng R-F, Chen W-Q (2014) Fundamental solutions to contact problems of a magneto-electro-elastic half-space indented by a semi-infinite punch. Int J Solids Struct 51:164-178.

[33] Zhou YT, Lee KY (2014) Investigation of frictional sliding contact problems of triangular and cylindrical punches on monoclinic piezoelectric materials. Mech Mater 69:237-250.

[34] Yilmaz KB, Çömez İ, Güler MA, Yildirim B (2019) Sliding frictional contact analysis of a monoclinic coating/isotropic substrate system. Mech Mater 137.

[35] Yildirim B, Yilmaz KB, Comez I, Guler MA (2019) Double frictional receding contact problem for an orthotropic layer loaded by normal and tangential forces. Meccanica 54:2183-2206.
[36] Çömez İ, Yilmaz KB (2019) Mechanics of frictional contact for an arbitrary oriented orthotropic material. ZAMM-J Appl Math Mech. Z Angew Math Mech 99:e201800084.

[37] Song HX, Ke LL, Su J, Yang J, Kitipornchai S, Wang YS (2020) Surface effect on the contact problem of a piezoelectric half-plane. Int J Solids Struct 185-186:380-393.

[38] Cao R, Li L, Li X, Mi C (2021) On the frictional receding contact between a graded layer and an orthotropic substrate indented by a rigid flat-ended stamp. Mech Mater 158.

[39] Çömez İ, Alinia Y, Güler MA, El-Borgi S (2021) Partial slip contact analysis for a monoclinic half plane. Math Mech Solids 26:401-421.

[40] Öner E (2021) Frictionless contact mechanics of an orthotropic coating/isotropic substrate system. Comput Concr 28:209-220.

[41] Erdogan F, Gupta GD (1972) On the numerical solution of singular integral equations. Quart Appl Math 29:525-534.

[42] Kefal A, Tessler A, Oterkus E (2017) An enhanced inverse finite element method for displacement and stress monitoring of multilayered composite and sandwich structures. Compos Struct 179:514-540.

[43] Sawant S, Muliana A (2008) A thermo-mechanical viscoelastic analysis of orthotropic materials. Compos Struct 83:61-72.

[44] Binienda WK, Pindera M (1994) Frictionless contact of layered metal-matrix and polymermatrix composite half planes. Compos Sci Technol 50:119-128.

[45] Çakıroğlu AO (1979) Elastik Yarım Düzleme Oturan Plaklarda Temas Problemi (in Turkish). Associate Professorship Thesis. Karadeniz Technical University, Trabzon.

[46] Geçit MR (1980) A tensionless contact without friction between an elastic layer and an elastic foundation. Int J Solids Struct 16:387-396.

[47] Civelek MB, Erdogan F (1976) Interface separation in a frictionless contact problem for an elastic layer. J Appl Mech 43:175-177.

[48] Civelek MB, Erdogan F, Cakiroglu AO (1978) Interface separation for an elastic layer loaded by a rigid stamp. Int J Eng Sci 16:669-679. 


\section{Appendix}

$$
K_{1}=\frac{\beta\left(-3+\kappa_{1}\right)\left(\left(-1+\mathrm{e}^{\Gamma h_{1}}\right) \mu_{0} \rho_{p}+\Gamma h_{1}\left(\left(\mathrm{e}^{z \Gamma}-\mathrm{e}^{\Gamma h_{1}}\right) g\left(-1+\kappa_{1}\right) \rho_{0}-\mathrm{e}^{z \Gamma} \mu_{0} \rho_{p}\right)\right)}{8\left(-1+\mathrm{e}^{\beta h_{1}}\right) \Gamma^{2}\left(-1+\kappa_{1}\right) \mu_{0}}
$$

$K_{2}=0$

$L_{1}=\frac{\left(\mathrm{e}^{z \Gamma}-\mathrm{e}^{\Gamma h_{1}}\right) g\left(-1+\kappa_{1}\right) \rho_{0}-\mathrm{e}^{z \Gamma} \mu_{0} \rho_{p}}{\Gamma\left(1+\kappa_{1}\right) \mu_{0}}$

$L_{2}=\frac{-\left(\mathrm{e}^{z \Gamma}-\mathrm{e}^{\Gamma h_{1}}\right) g(-\beta+\Gamma)\left(-1+\kappa_{1}\right) \rho_{0}+\left(\beta-\mathrm{e}^{z \Gamma} \beta+\mathrm{e}^{z \Gamma} \Gamma\right) \mu_{0} \rho_{p}}{\beta(\beta-\Gamma) \Gamma\left(1+\kappa_{1}\right) \mu_{0}}$ 